\title{
Isolation of novel microsatellites for the howler monkey bot fly
}

\author{
Cuterebra baeri (Diptera: Cuterebrinae)
}

\author{
Katharine Milton · Jeffrey D. Lozier • \\ Eileen A. Lacey
}

Received: 8 November 2010/ Accepted: 25 November 2010/Published online: 16 December 2010

(C) The Author(s) 2010. This article is published with open access at Springerlink.com

\begin{abstract}
The bot fly Cuterebra baeri is a host-specific parasite of howler monkeys (Alouatta spp.). To explore relationships between populations of these taxa on Barro Colorado Island, Panama, we developed 22 microsatellite loci for C. baeri. Twelve of these loci were polymorphic; the mean number of alleles per locus was $3.73 \pm 0.3$ (range $=2-5$ ), with a mean observed heterozygosity of $0.428 \pm 0.052$ (range $=0.067-0.683$ ). Overall, variability among the 61 larvae sampled was low, perhaps reflecting the isolation of this island population. Analyses of a subset of these individuals revealed that $C$. baeri larvae parasitizing the same howler monkey were more closely related to each other than were larvae from different monkeys. Future studies will use these loci to explore such host-parasite relationships in greater detail.
\end{abstract}

Keywords Cuterebra baeri - Howler monkey bot fly · Microsatellites · Barro Colorado Island

Cuterebrid bot flies (Oestridae: Cuterebrinae) are a specialized lineage of blow-fly-like Diptera endemic to the New World (Catts 1982). The great majority of species in

K. Milton ( ()

Department of Environmental Science, Policy and Management, University of California, Berkeley, CA 94720, USA

e-mail: kmilton@berkeley.edu

J. D. Lozier

Department of Entomology, University of Illinois, Urbana, IL 61801, USA

E. A. Lacey

Museum of Vertebrate Zoology and Department of Integrative Biology, University of California, Berkeley, CA 94720, USA the subfamily Cuterebrinae belong to the genus Cuterebra. Cuterebra baeri is the only member of this genus known to use primate hosts, specifically members of the neotropical genus Alouatta, commonly known as howler monkeys (Catts 1982; Milton 1996). The population of mantled howler monkeys (A. palliata) on Barro Colorado Island (BCI), Panama, has been the subject of numerous longterm ecological and behavioral studies (e.g., Carpenter 1934; Milton 1980). Detailed life-history observations suggest that parasitism by $C$. baeri is an important source of mortality in this primate population (Milton 1996). Comparative analyses of population genetic structure in these species, including patterns of individual relatedness and dispersal, would generate important new insights into this host-parasite interaction. Microsatellite markers have already allowed the characterization of genetic relationships among howler monkeys on BCI (Milton et al. 2009). Here we present a set of novel di-, tri-, and tetranucleotide microsatellite loci for $C$. baeri that can be used to characterize genetic structure within the parasite component of this interspecific interaction.

We extracted genomic DNA from two $C$. baeri larvae using the DNeasy tissue kit (Qiagen, Valencia, CA). We developed a microsatellite library following a modified version of the protocol of Glenn and Schable (2005). Briefly, DNA was digested with the restriction enzyme RsaI (New England Biolabs), ligated to double-stranded linkers [SimpleX-3F 5'-AAAACGTGCTGCGGAACT-3' and SimpleX-3R 5'- AGTTCCCAGCACG], denatured, hybridized to multiple biotinylated microsatellite oligonucleotides $\left[(\mathrm{AG})_{12},(\mathrm{TG})_{12},(\mathrm{AAC})_{6},(\mathrm{AAG})_{8},(\mathrm{AAT})_{12}\right.$, $(\mathrm{ACT})_{12}, \quad(\mathrm{ATC})_{8}, \quad(\mathrm{AAAC})_{6}, \quad(\mathrm{AAAG})_{6}, \quad(\mathrm{AATC})_{6}$, $(\text { AATG })_{6},(\text { ACAG })_{6},(\text { ACCT })_{6}, \quad(\text { ACTC })_{6},(\text { ACTG })_{6}$, AAAT $\left.)_{8},(\mathrm{AACT})_{8},(\mathrm{AAGT})_{8},(\mathrm{ACAT})_{8},(\mathrm{AGAT})_{8}\right]$, and then captured on magnetic streptavidin beads (Dynal 


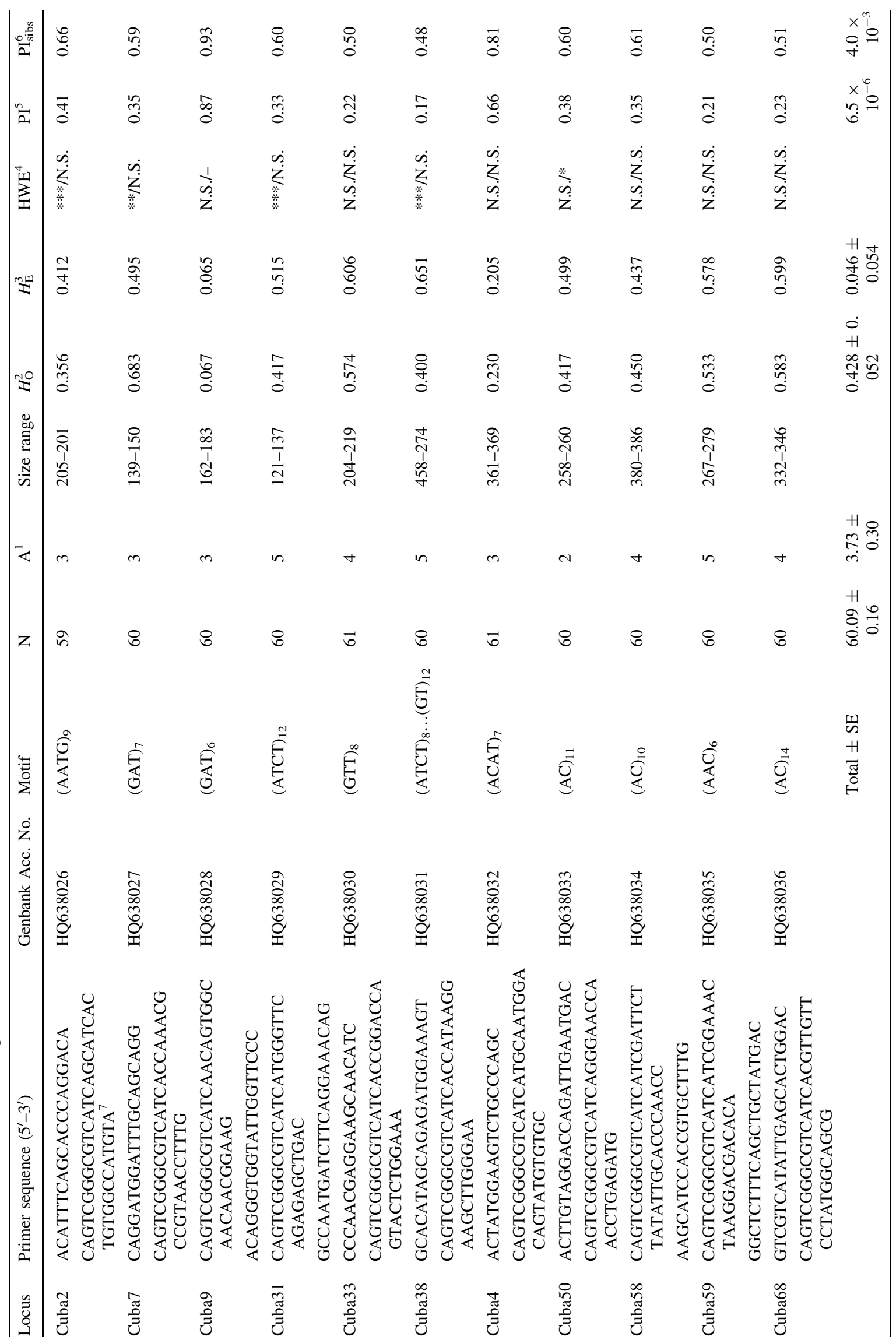




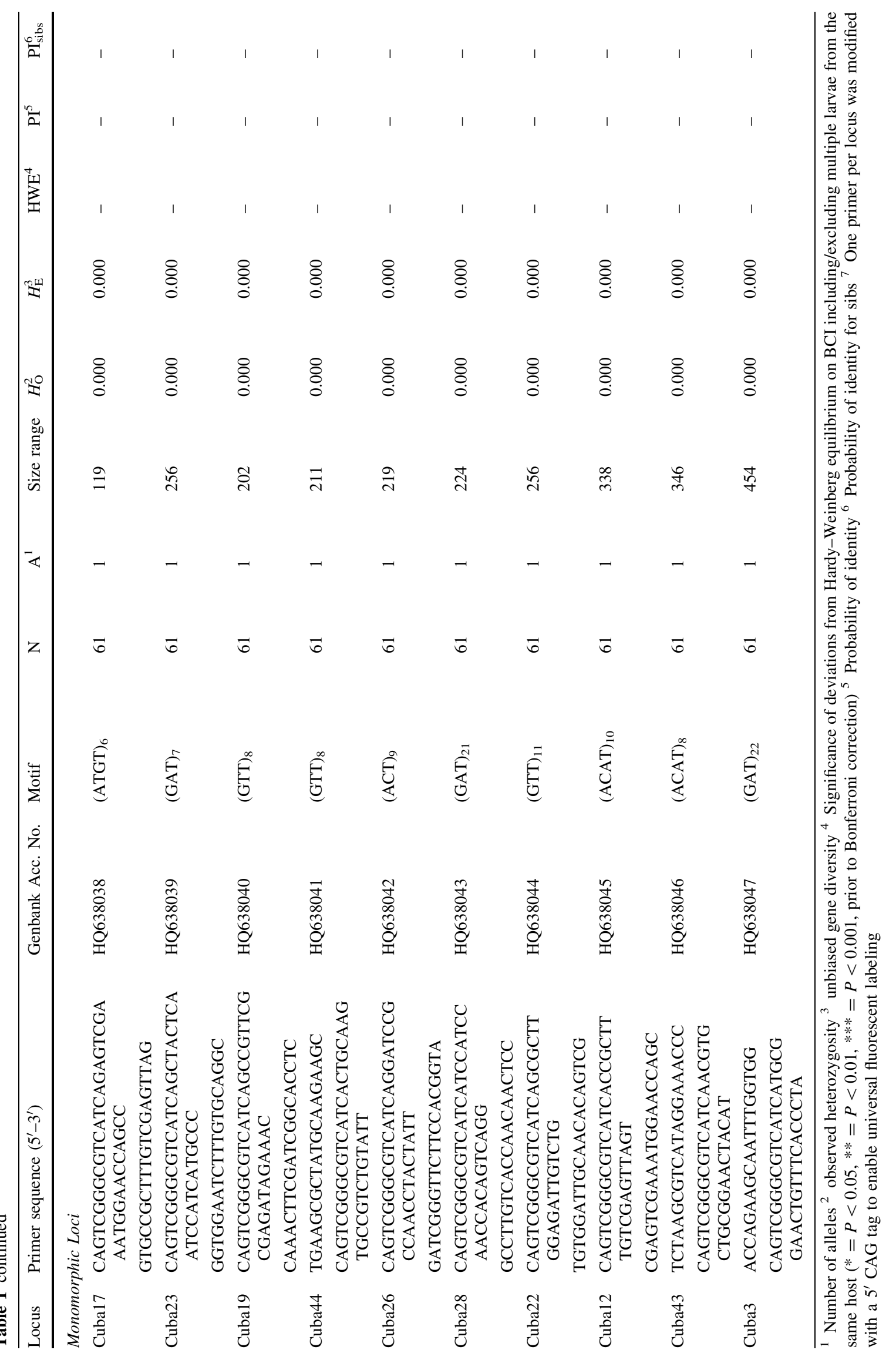


Biotech). Microsatellite-enriched DNA was retrieved from the beads and amplified via PCR primed with SimpleX-3F. Amplicons were sequenced on a 454 system (titanium chemistry) following standard protocols (Roche 454 Life Sciences, Branford CT). Sequences were subjected to a $3^{\prime}$ quality trim in which only 1 of the last 25 bases of the sequence was ambiguous or had a quality score $<20$. CAP3 (Huang and Madan 1999) was then used to assemble sequences at $98 \%$ sequence identity using a minimal overlap of 75 base pairs. Sequences were searched for the presence of microsatellites using MSATCOMMANDER v0.8.1 (Faircloth 2008), after which primers were designed with Primer3. One primer from each pair was modified on the $5^{\prime}$ end with an engineered sequence (CAG tag $5^{\prime}$ CAGTCGGGCGTCATCA-3 ${ }^{\prime}$ ) to enable use of a fluorescently labeled primer (identical to the $\mathrm{CAG}$ tag) during genotyping of larvae.

Forty-eight primer pairs were tested using DNA obtained from eight $C$. baeri larvae. PCR amplifications were performed in a $12.5 \mu \mathrm{L}$ volume $(10 \mathrm{mM}$ Tris $\mathrm{pH} 8.4$, $50 \mathrm{mM} \mathrm{KCl}, 25.0 \mu \mathrm{g} / \mathrm{ml} \mathrm{BSA}, 0.4 \mu \mathrm{M}$ unlabeled primer, $0.04 \mu \mathrm{M}$ tag labeled primer, $0.36 \mu \mathrm{M}$ universal dyelabeled primer, $3.0 \mathrm{mM} \mathrm{MgCl} 2,0.8 \mathrm{mM}$ dNTPs, 0.5 units JumpStart Taq DNA Polymerase (Sigma), and $\sim 20 \mathrm{ng}$ DNA template) using an Applied Biosystems GeneAmp 9700. Touchdown thermal cycling programs encompassing a $10^{\circ} \mathrm{C}$ span of annealing temperatures (start temperatures $55-58{ }^{\circ} \mathrm{C}$ ) were used for all loci. Touchdown cycling parameters consisted of 20 cycles of $96^{\circ} \mathrm{C}$ for $30 \mathrm{~s}$, annealing (temperature decreased by $0.5^{\circ} \mathrm{C} /$ cycle) for $30 \mathrm{~s}$, and $72{ }^{\circ} \mathrm{C}$ for $30 \mathrm{~s}$, followed by 20 cycles of $96{ }^{\circ} \mathrm{C}$ for $30 \mathrm{~s}, 48{ }^{\circ} \mathrm{C}$ for $30 \mathrm{~s}$, and $72{ }^{\circ} \mathrm{C}$ for $30 \mathrm{~s}$. PCR products were run on an ABI-3130xl sequencer using a Naurox size standard prepared as described in DeWoody et al. (2004), except that unlabeled primers began with GTTT. Results were analyzed using GeneMapper v3.7 (Applied Biosystems). Population genetic statistics were calculated with GENEPOP v4.0 (Rousset 2008) and GENALEX v4.6 (Peakall and Smouse 2006).

Twenty-two of the primer pairs tested produced high quality PCR products and were thus used to assess variability in a larger sample of 61 fly larvae collected from 2003-2009 (57 larvae from BCI, 4 from a mainland sample). Of these, 12 loci were polymorphic. The remaining 10 loci were monomorphic across all 61 of the larvae genotyped. Among the polymorphic loci identified, measures of genetic diversity were generally low (e.g., mean observed heterozygosity $=0.428 \pm 0.052$; Table 1 ), perhaps reflecting the physical isolation of $\mathrm{BCI}$ for the past $\sim 100$ years. No significant linkage disequilibrium was detected among loci (all $P>0.05$ ). When all BCI larvae were considered (mainland individuals excluded), 4 loci were found to deviate from Hardy-Weinberg expectations

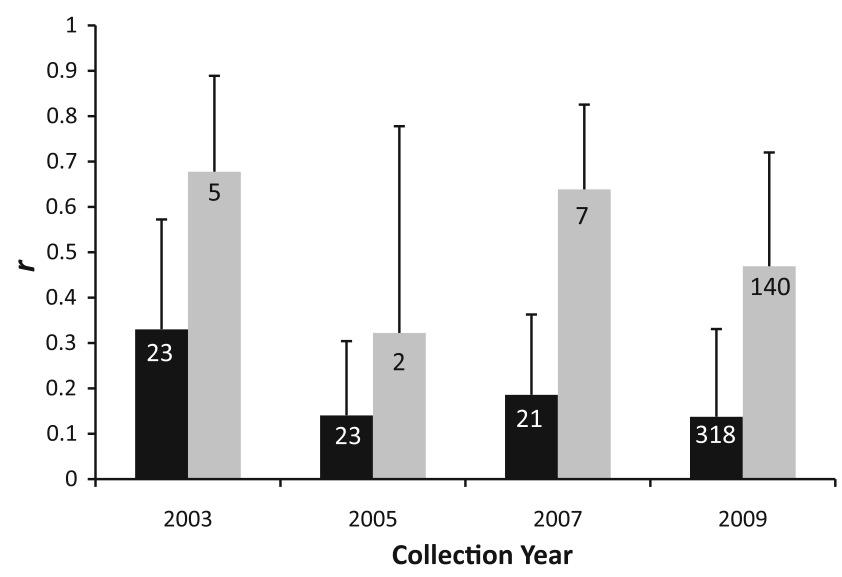

Fig. 1 Mean $( \pm 1 \mathrm{SD})$ pairwise relatedness of bot fly larvae sampled from the same (gray bars) versus different (black bars) howler monkey hosts. Data from each year sampled were analyzed separately. The number of larvae used in each comparison is shown

(Table 1). Based on visual inspection of data, we suspect that such deviations resulted from our sampling multiple larvae per host (i.e., probable offspring of the same female fly) or from pooling samples over multiple years, rather than from problems with the loci per se (e.g., null alleles). When these analyses were repeated using only 1 larva per host, only 1 locus deviated from HW expectations; after Bonferroni correction of $P$ values, no significant deviations from HW expectations were evident (Table 1).

To begin characterizing the genetic structure of $C$. baeri on BCI, we compared coefficients of relatedness (r) among larvae from the same versus different host monkeys; estimates of $r$ were generated using ML-RELATE (Kalinowski et al. 2006), with reference population allele frequencies estimated from the full BCI data set. In all years, r-values for larvae collected from the same host were consistently greater than those for larvae from different hosts (Fig. 1), although at this point statistical analyses would be premature. However, this result is consistent with the hypothesis that multiple larvae on each host often come from eggs laid by the same adult fly, and is a likely explanation for the observed HWE deviations. Together, the markers are capable of distinguishing individuals with high probability (Table 1). Additional sampling of bot flies, including increased sampling of mainland (non-BCI) populations, will provide a more complete picture of genetic variability in this species; the microsatellite loci described here are essential to efforts to understand the genetic dynamics of the relationship between $C$. baeri and its primate hosts.

Acknowledgments We thank the Autoridad Nacional del Ambiente (ANAM) of Panama and the Smithsonian Tropical Research Institute for their facilitation of this research, Kip Will for laboratory facilities, Mae Huo for extraction of larval DNA, Stacey Lance, Savanna River 
Ecology Laboratory and Ken Jones, Georgia Genomics Laboratory, University of Georgia for microsatellite development and Alexander Purcell and Neil Tsutsui for helpful suggestions. Research funding for $\mathrm{KM}$ was provided by the California Agricultural Experimental Station at UC Berkeley.

Open Access This article is distributed under the terms of the Creative Commons Attribution Noncommercial License which permits any noncommercial use, distribution, and reproduction in any medium, provided the original author(s) and source are credited.

\section{References}

Catts EP (1982) Biology of new world bot flies: cuterebridae. Annu Rev Entomol 27:313-338

DeWoody AJ, Schupp J, Kenefic L, Busch J, Murfitt L, Keim P (2004) Universal method for producing ROX-labeled size standards suitable for automated genotyping. BioTechniques $37: 348-350$

Faircloth BC (2008) MSATCOMMANDER: detection of microsatellite repeat arrays and automated, locus-specific primer design. Mol Ecol 8:92-94
Glenn TC, Schable NA (2005) Isolating microsatellite DNA loci. Methods Enzymol 395:202-222

Huang X, Madan A (1999) CAP3: a DNA sequence assembly program. Genome Res 9:868-877

Kalinowski ST, Wagner AP, Taper ML (2006) ML-Relate: A computer program for maximum likelihood estimation of relatedness and relationship. Mol Ecol Notes 6:576-579

Milton K (1980) The foraging strategy of howler monkeys. Columbia University Press, New York

Milton K (1996) Effects of bot fly (Alouattamyia baeri) parasitism on a free-ranging howler monkey (Alouatta palliata) population in Panama. J Zool 239:39-63

Milton K, Lozier JD, Lacey EA (2009) Genetic structure of an isolated population of mantled howler monkeys (Alouatta palliata) on Barro Colorado Island, Panama. Cons Genetics 10:347-358

Peakall R, Smouse PE (2006) GENALEX 6: genetic analysis in Excel. Population genetic software for teaching and research. Molec Ecol Notes 6:288-295

Rousset F (2008) GENEPOP'007: a complete re-implementation of the GENEPOP software for Windows and Linux. Mol Ecol Res 8:103-106 